\title{
Effect of cytokines and ultraviolet $B$ radiation on the promoter activity of the metallothionein gene in keratinocytes
}

\author{
Hiromi Narumi*, Hajime Nakano, Takahide Kaneko, Koji Nakajima, Yasushi Matsuzaki, \\ Takayuki Aizu, Daisuke Sawamura, Katsumi Hanada \\ Department of Dermatology, Hirosaki University Graduate School of Medicine, Hirosaki, Japan

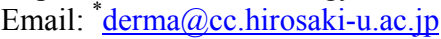 \\ Received 18 April 2013; revised 19 May 2013; accepted 10 June 2013 \\ Copyright (C) 2013 Hiromi Narumi et al. This is an open access article distributed under the Creative Commons Attribution License, \\ which permits unrestricted use, distribution, and reproduction in any medium, provided the original work is properly cited.
}

\begin{abstract}
Metallothionein (MT) has many functions that are modulated by several factors, including ultraviolet (UV) radiation and cytokines. We thought that these diverse functions of MT might reflect the specific regulatory mechanisms of its expression. To understand some of the molecular mechanisms underlying MT expression, we examined the effects of several cytokines and UVB on the promoter activity of the MT gene. First, we introduced the MT promoter construct into the HaCaT keratinocytes and treated them with various concentrations of interleukin-1 $\alpha$ (IL-1 $\alpha$ ) and IL-6. The addition of IL-1 $\alpha$ and IL-6 led to an increase in the promoter activity of the MT gene. UVB is known to induce MT expression in epidermal keratinocytes, and IL-6 is a possible mediator of MT induction by UV radiation. Therefore, we investigated whether UVB could induce MT promoter activity. Our results showed, interestingly, that UVB radiation has no or little effect on the promoter activity. This suggested a complex molecular regulation of the MT gene.
\end{abstract}

Keywords: Sunburn; Cytokine; Epidermis; Ultraviolet Light; Promoter

\section{INTRODUCTION}

Metallothionein (MT) is a ubiquitously distributed, cysteine-rich, low molecular weight protein having a high binding capacity for metals such as zinc, copper, and cadmium. It plays a role in zinc homeostasis and detoxification of heavy metals [1]. Several studies have shown that MT acts as a reactive oxygen species scavenger [2]

"Corresponding author. and MT induction has protective effects against oxidative stresses such as anticancer drugs and ultraviolet (UV) radiation [3]. MT gene expression is induced not only by heavy metals but also by various stress-inducing agents such as UV [4] and X-ray radiation [5]. We found that $\beta$-thujaplicin induced MT expression in keratinocytes, both in vitro and in vivo, and thereby reduced UVB irradiation-induced apoptosis [6]. Furthermore, a number of cytokines, including interferon- $\alpha$ and $\beta$, tumor necrosis factor- $\alpha$, interleukin-1 (IL-1), and IL-6, increase MT expression, suggesting that MT expression also involves additional functions, including immunomodulation, cell growth, and cell differentiation [7].

We thought that these diverse functions of MT might reflect specific regulatory mechanisms of its expression. We have recently cloned the promoter region of the MT gene and performed a functional assay [8]. Thus, to understand some of the molecular mechanism underlying MT expression, we focused on the effects of several cytokines and UVB radiation on the promoter activity of the MT gene.

\section{MATERIALS AND METHODS}

\subsection{Cell Culture}

The spontaneously transformed human epidermal keratinocyte cell line, HaCaT, (kindly provided by Dr. Husenig) was cultured in Dulbecco's modified minimal essential medium supplemented with $10 \%$ fetal calf serum, $1 \%$ l-glutamine, and $1 \%$ antibiotic/antimycotic solution. The cells were maintained at $37^{\circ} \mathrm{C}$ in a humidified atmosphere containing $5 \% \mathrm{CO}_{2}$. The viability of the cells treated with cytokines and UVB radiation for $24 \mathrm{~h}$ was approximately $95 \%$, as determined by trypan blue exclusion staining. 


\subsection{Plasmid Constructs}

The vector p5'MT-CAT, containing the 5'-flanking region of the MT-IIA gene, was generated by ligating a HindIII/BamHI fragment of the MT-IIA promoter, spanning from -764 to +79, (American Type Culture Collection, Rockville, MD, USA) to the pBS0CAT reporter construct [8]. The integrity of the reporter constructs was confirmed by direct sequencing.

\subsection{UVB Radiation Source}

As the UVB source, a bank of 7 fluorescent sunlamps (FL20SE.30; Toshiba Medical Supply, Tokyo, Japan) emitting rays of $275-305 \mathrm{~nm}$ and peaking at $305 \mathrm{~nm}$ was used [9]. The radiation dose was measured using a radiometer (UVR-3036/S; Clinical Supply, Kakamigahara, Japan).

\subsection{Transient Transfection Experiments}

Transient transfection was performed using Trans IT transfection reagent (PanVera, Madison, WI, USA). Briefly, $60 \%$ confluent $\mathrm{HaCaT}$ cells were placed in a $60-\mathrm{mm}$ dish and then incubated with $0.5 \mu \mathrm{g}$ reporter gene and the transfection reagent for $6 \mathrm{~h}$. For monitoring the transfection efficiency, the cells were cotransfected with the RSV- $\beta$-galactosidase expression vector. The cells were treated with various concentrations of cytokines for $24 \mathrm{~h}$. The cells were also irradiated with UVB, followed by further incubation with the medium for $24 \mathrm{~h}$. The treated cells were rinsed twice with phosphate buffered saline and then lysed in $200 \mathrm{ml}$ of reporter lysisbuffer (Promega, Madison, WI, USA). As positive control, we used the transfected cells that were incubated with $10 \mu \mathrm{M}$ of cadmium.

\subsection{Chloramphenicol Acetyltransferase (CAT) Assays}

The CAT activity, an indicator of the promoter activity, was determined by incubation with $\left[{ }^{14} \mathrm{C}\right]$-chloramphenicol [8]. The $\beta$-galactosidase activity of all the samples were measured, and each CAT activity value was corrected for the $\beta$-galactosidase activity in the corresponding cell culture transfected in parallel. CAT activity was quantified by measuring the amount of $\left[{ }^{14} \mathrm{C}\right]$-chloramphenicol converted to the monoacetylated form. The promoter activity was expressed as the rate of CAT activity of the sample to that of the positive control $(10 \mu \mathrm{M}$ of cadmium).

\section{RESULTS}

\subsection{Effect of IL-1 $\alpha$, IL-6, and IL-10 (Figure 1)}

First, we introduced the MT promoter construct into the
$\mathrm{HaCaT}$ cells and treated them with various concentrations of IL-6, IL-1, and IL-10. After the addition of IL- $1 \alpha$, the promoter activity of the MT gene increased in a dose-dependent manner and reached the maximum at a concentration of $10 \mathrm{ng} / \mathrm{ml}$. IL- 6 induced the promoter activity at an even lower concentration than IL- $1 \alpha$. On the other hand, IL-10 did not activate the promoter.

\subsection{Effect of UVB (Figure 2)}

Next, we examined the effect of UVB radiation on the promoter activity of the MT gene. We harvested the HaCaT cells $24 \mathrm{~h}$ after UVB irradiation. The results showed

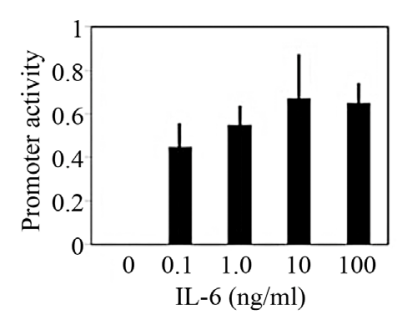

(a)

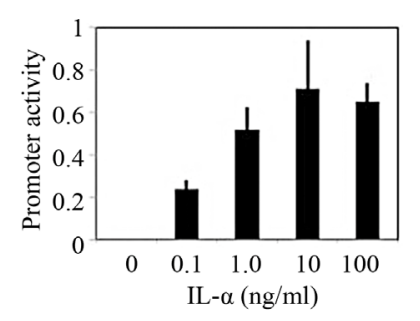

(b)

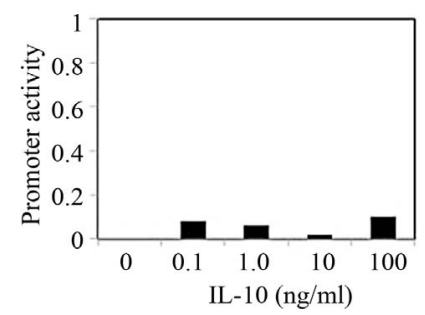

(c)

Figure 1. Effects of IL-1 $\alpha$, IL-6, and IL-10 on the promoter activity of the MT gene. We introduced the MT promoter construct into the $\mathrm{HaCaT}$ cells and treated them with various concentrations of IL-1 $\alpha$ (a), IL-6 (b), and IL-10 (c). The activity levels are expressed as mean (SD).

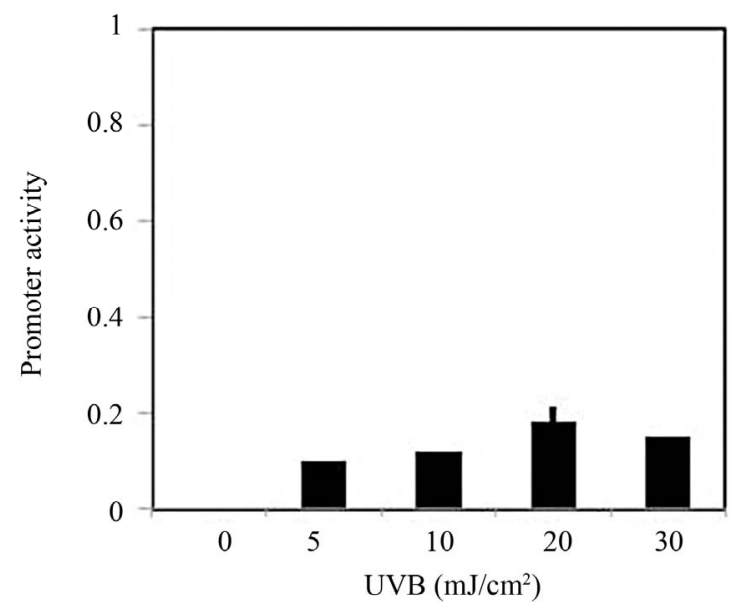

Figure 2. Effects of UVB on the promoter activity of the MT gene. We introduced the MT promoter construct into the HaCaT cells and harvested the cells $24 \mathrm{~h}$ after UVB irradiation. The activity levels are expressed as mean (SD). 
that UVB had no or little enhancing effect on the promoter activity at doses ranging from 5 to $30 \mathrm{~mJ} / \mathrm{cm}^{2}$. Furthermore, we collected the treated cells several times after irradiation, but we could not observe any strong induction of the promoter activity.

\section{DISCUSSION}

IL-1 $\alpha$ has many physiological functions in the immune, metabolic, and hematopoietic systems. Keratinocytes are a major source of IL-1 $\alpha$. As a proinflammatory cytokine, IL-1 $\alpha$ is involved in inflammatory and allergic skin diseases such as psoriasis and contact dermatitis. It also plays an important role in many recently defined autoinflammatory diseases [10]. IL-6 acts both as a pro- and anti-inflammatory cytokine. It is also secreted by keratinocytes, and it stimulates the immune response in both normal and abnormal skin conditions [11]. Furthermore, IL- $1 \alpha$ and IL- 6 are known to increase the MT gene expression and thereby, its protein expression. In this study, we first examined the effects of IL- $1 \alpha$ and IL- 6 on the MT promoter activity in epidermal keratinocytes. Our results show that both cytokines induced promoter activity in a dose-dependent manner. We also investigated the effect of IL-10 on MT expression, and as expected, we did not find any significant effect of IL-10 on the promoter activity.

The epidermis is the outermost layer of the skin. Keratinocytes form a majority, i.e., about $95 \%$, of the epidermis' cells and are major targets of solar radiation. UVB benefits humans by catalyzing the production of vitamin $\mathrm{D}$, but it also causes sunburn, photoaging, and skin cancers. UVB is responsible for the production of many cytokines in the keratinocytes [12]. Furthermore, UVB is known to induce MT expression in the epidermal keratinocytes, and IL-6 is a possible mediator of MT induction by UV radiation [13]. Therefore, we investigated whether UVB radiation could induce MT promoter activity. Our results showed, interestingly, that UVB radiation has no or little effects on the promoter activity, although IL-6 clearly induced the promoter activity of the MT gene in our study. This discrepancy implies non-transcriptional mechanisms such as an increase in mRNA stability, suggesting complex molecular regulation of the MT gene.

\section{ACKNOWLEDGEMENTS}

The authors would like to thank Ms Yuka Toyomaki, Mrs Yukiko Tamura, Mrs Yuriko Takagi, and Ms Nanako Seitoh for their excellent technical assistance. This work was supported in part by Grants-in-Aid from the Ministry of Education, Science, Sports, and Culture of Japan.

\section{REFERENCES}

[1] Masters, B.A., Kelly, E.J., Quaife, C.J., Brinster, R.L. and
Palmiter, R.D. (1994) Targeted disruption of metallothionein I and II genes increases sensitivity to cadmium. Proceedings of the National Academy of Sciences of the United States of America, 91, 584-588. doi:10.1073/pnas.91.2.584

[2] Lazo, J.S., Kondo, Y., Dellapiazza, D., Michalska, A.E., Choo, K.H. and Pitt, B.R. (1995) Enhanced sensitivity to oxidative stress in cultured embryonic cells from transgenic mice deficient in metallothionein I and II genes. Journal of Biological Chemistry, 270, 5506-5510. doi:10.1074/jbc.270.10.5506

[3] Hanada, K., Sawamura, D., Tamai, K., Baba, T., Hashimoto, I., Muramatsu, T., Miura, N. and Naganuma, A. (1998) Novel function of metallothionein in photoprotection: Metallothionein-null mouse exhibits reduced tolerance against ultraviolet B injury in the skin. Journal of Investigative Dermatology, 111, 582-585. doi:10.1046/j.1523-1747.1998.00342.x

[4] Angel, P., Poting, A., Mallick, U., Rahmsdorf, H.J., Schorpp, M. and Herrlich, P. (1986) Induction of metallothionein and other mRNA species by carcinogens and tumor promoters in primary human skin fibroblasts. $\mathrm{Mo}$ lecular and Cellular Biology, 6, 1760-1766.

[5] Shiraishi, N., Yamamoto, H., Takeda, Y., Kondoh, S., Hayashi, H., Hashimoto, K. and Aono, K. (1986) Increased metallothionein content in rat liver and kidney following X-irradiation. Toxicology and Applied Pharmacology, 85, 128-134. doi:10.1016/0041-008X(86)90106-7

[6] Baba, T., Nakano, H., Tamai, K., Sawamura, D., Hanada, K., Hashimoto, I. and Arima, Y. (1998) Inhibitory effect of beta-thujaplicin on ultraviolet B-induced apoptosis in mouse keratinocytes. Journal of Investigative Dermatol$o g y$, 110, 24-28. doi:10.1046/j.1523-1747.1998.00078.x

[7] Sato, M., Sasaki, M. and Hojo, H. (1994) Differential induction of metallothionein synthesis by interleukin-6 and tumor necrosis factor-alpha in rat tissues. International Journal of Immunopharmacology, 16, 187-195. doi:10.1016/0192-0561(94)90075-2

[8] Nakano, H., Ikenaga, S., Aizu, T., Kaneko, T., Matsuzaki, Y., Tsuchida, S., Hanada, K. and Arima, Y. (2006) Human metallothionein gene expression is upregulated by beta-thujaplicin: Possible involvement of protein kinase $\mathrm{C}$ and reactive oxygen species. Biological and Pharmaceutical Bulletin, 29, 55-59. doi:10.1248/bpb.29.55

[9] Hanada, K. (2000) Photoprotective role of metallothionein in UV-injury-metallothionein-null mouse exhibits reduced tolerance against ultraviolet-B. Journal of Dermatological Science, 23, S51-S56. doi:10.1016/S0923-1811(99)00078-X

[10] Goldbach-Mansky, R. and Kastner, D.L. (2009) Autoinflammation: The prominent role of IL-1 in monogenic autoinflammatory diseases and implications for common illnesses. Journal of Allergy and Clinical Immunology, 124, 1141-1149. doi:10.1016/j.jaci.2009.11.016

[11] Sawamura, D., Meng, X., Ina, S., Sato, M., Tamai, K., Hanada, K. and Hashimoto, I. (1998) Induction of keratinocyte proliferation and lymphocytic infiltration by in vivo introduction of the IL- 6 gene into keratinocytes and 
possibility of keratinocyte gene therapy for inflammatory skin diseases using IL-6 mutant genes. Journal of Immunology, 161, 5633-5639.

[12] Vicentini, F.T., He, T., Shao, Y., Fonseca, M.J.V., Verri Jr., W.A., Fisher, G.J. and Xu, Y. (2011) Quercetin inhibits UV irradiation-induced inflammatory cytokine production in primary human keratinocytes by suppressing

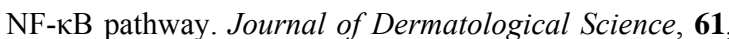
162-168. doi:10.1016/j.jdermsci.2011.01.002

[13] Nishimura, N., Reeve, V.E., Nishimura, H., Satoh, M. and Tohyama, C. (2000) Cutaneous metallothionein induction by ultraviolet B irradiation in interleukin-6 null mice. Journal of Investigative Dermatology, 114, 343348. doi:10.1046/j.1523-1747.2000.00862.x 